\title{
Vegetation Database of Oak Communities in Turkey
}

\author{
Emin Uğurlu
}

\begin{abstract}
In Turkey, approximately 20,000 vegetation relevés do exist in total. However, there is no central database for Turkish vegetation relevés at present (2011). I started building the Vegetation Database of Oak Communities in Turkey (GIVD ID AS-TR-002) from published and unpublished data such as master and $\mathrm{PhD}$ theses, reports and articles in local and international journals. In total, 1,181 relevés were entered in TURBOVEG format for oak vegetation relevés, including woodlands and forests. Plots were georeferenced using the Google Earth plugin integrated in the TURBOVEG software. Typical header data, such as altitude or aspect were entered when available. Most of the relevés belong to the vegetation classes Quercetea ilicis and Quercetea pubescentis.
\end{abstract}

Keywords: Anatolia; Quercetea ilicis, Quercetea pubescentis; relevé; TURBOVEG.

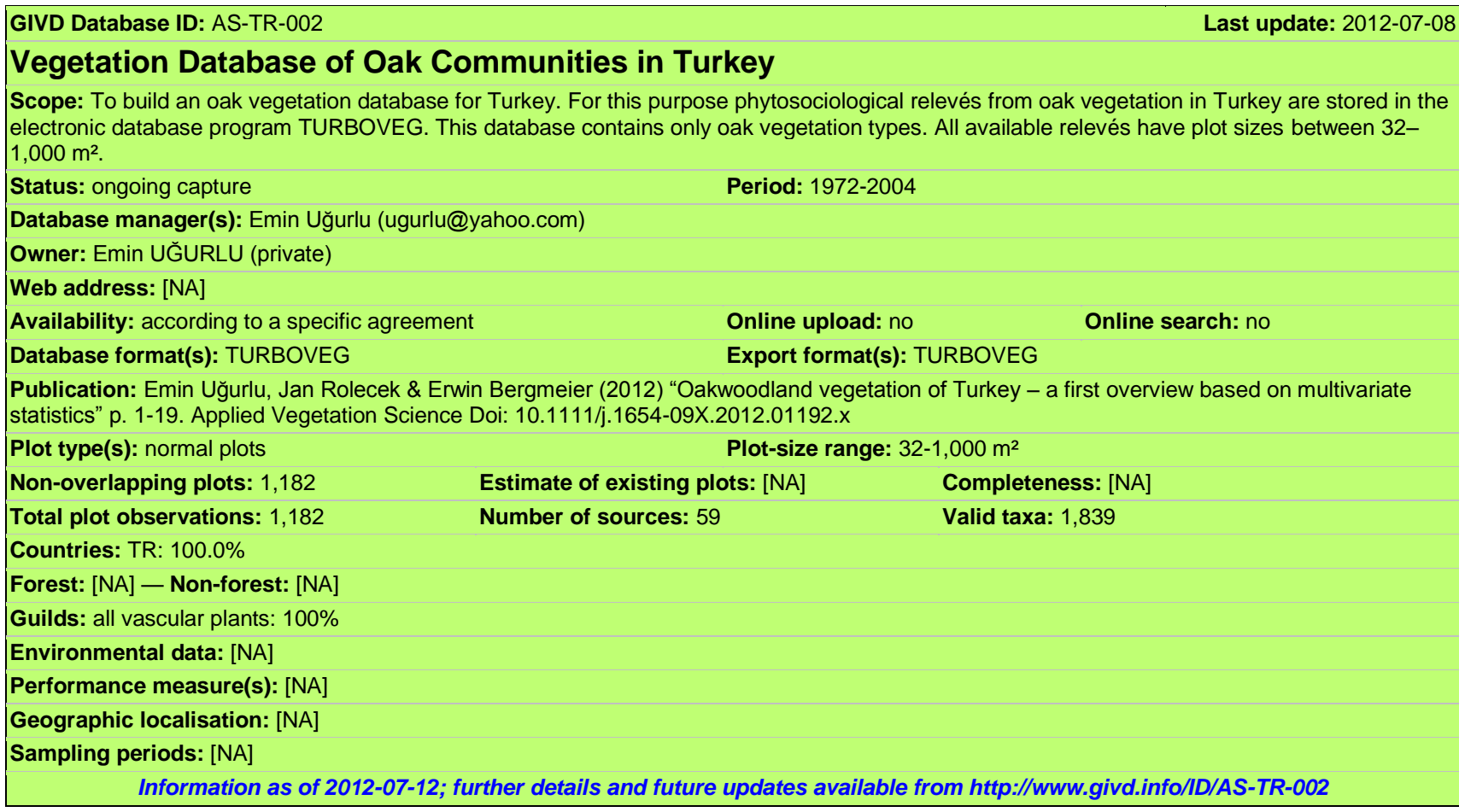

Emin Uğurlu (ugurlu@yahoo.com )

Department of Biology, Celal Bayar University Science and Art Faculty, Muradiye Campus, 45100 Manisa, TURKEY 